\section{ECCOMAS}

\section{Proceedia}

COMPDYN 2021

$8^{\text {th }}$ ECCOMAS Thematic Conference on Computational Methods in Structural Dynamics and Earthquake Engineering M. Papadrakakis, M. Fragiadakis (eds.) Streamed from Athens, Greece, 28 - 30 June 2021

\title{
TUNING THE LATERAL RESPONSE OF UNBONDED FIBER REINFORCED ELASTOMERIC ISOLATORS (U-FREIS): EXPERIMENTAL - NUMERICAL FINDINGS
}

\author{
Simone Galano ${ }^{1,2}$, Andrea Calabrese ${ }^{2}$, Daniele Losanno ${ }^{1}$ \\ 1, Department of Structures for Engineering \& Architecture, University of Naples Federico II \\ Napoli, via Claudio 21, Naples 80125, Italy \\ \{simone.galano,daniele.losanno\}@unina.it \\ ${ }^{2}$, Department of Civil Engineering \& Construction Engineering Management, California State University \\ Long Beach \\ Long Beach, CA, USA \\ \{Simone.Galano,Andrea.Calabrese\}@csulb.edu
}

\begin{abstract}
Fiber-reinforced elastomeric isolators (FREIs) are elastomeric devices which have been introduced as a low-cost alternative to the well-known steel-reinforced elastomeric isolators (SREIS). As common in rubber-based devices, the application of FREIs to lightweight structures is challenging: when the mass is limited, the resulting slender bearings tend to become unstable under large horizontal displacements. On the basis of numerical and experimental findings, this research work aims to demonstrate a simple to implement and low-cost approach to extend the application of FREIS to lightweight structures. The technique here discussed allows (i) to reduce the horizontal stiffness of FREIs, (ii) to increase the stability range of the bearings, and (iii) to obtain a desired hardening response for large lateral deformations, with no instability.
\end{abstract}

Keywords: seismic isolation, elastomeric isolators, fiber-reinforced elastomeric isolators, low-cost seismic isolation, finite element analysis.

\section{INTRODUCTION}

Fiber-reinforced elastomeric isolators (FREIs) are made by bonding together layers of elastomer and layers of carbon or glass fibers. These bearings were introduced as a low-cost alternative to common steel-reinforced elastomeric isolators (SREIs) [1]. Several studies have shown the advantages of using FREIs in common base isolation applications. In particular, it has been proved that FREIs can be made using a cold vulcanization process, which is less expensive than the vulcanization process used for SREIs [2]. With the same process it is possible to manufacture eco-friendly and low-cost devices using elastomeric layers of recycled rubber and readily available fiber fabrics [3, 4].

FREIs are generally used in unbonded applications (U-FREIs). In this configuration, the imposed shear load is transferred thought friction [5]. U-FREIs show an unique rollover deformation when they are displaced under lateral loads ( [1], [6]): the top and bottom sides of the bearings detach from the horizontal subgrades, while the lateral surfaces of the bearings rotate until they touch the horizontal plates [7]. Depending on the aspect ratio of the bearing and the applied axial load, the lateral response of a FREI can become unstable for a lateral displacement larger than half of its base ( [8], [9]). Analytical models for the static and dynamic response of rubber bearings have been 
proposed ( $[10,11,12,13,14])$. But the challenging lateral response of the bearings has prompted several experimental ( [15], [16], [17], [18], [19], [20]) and numerical studies ( $[21,22])$.

For elastomeric base isolation systems, the period of isolation is function of the applied vertical load ( [23], [24]). Ideally, a rubber-based device should be flexible, stable under large lateral deformations, and should show hardening for very large displacements to contain the deformation of the bearing and to prevent damage. With this aim in mind, different geometric configurations have been tested, most of which have been obtained by creating vertical holes in FREIs to reduce their horizontal stiffness, with a minimal impact on the stability of the bearing under lateral loads ( [25], [26], [27], [28]). A different concept for the modification of the response of U-FREIs is discussed in the present work. In particular, the effects of horizontal holes on the lateral response of rubber-based devices, introduced by the authors earlier [29], are discussed. Results of experimental and numerical analyses are presented to show that by changing the geometry of a FREI, it is possible to obtain:

- a controlled reduction of the horizontal stiffness.

- hardening under large lateral deformations.

- a wide range of stable response.

\section{EXPERIMENTAL TESTS}

\subsection{Description of the tested samples}

The bearings tested in this study were manufactured by Kirkhill Manufacturing Company, Downey, CA following Caltrans specifications [30]. As per specifications, laminated pads were made by bonding together elastomeric layers and fabric reinforcements. Each of the tested bearings was cut from a pad of bigger dimensions. Each sample was made by bonding 9 layers of neoprene to 8 layers of bidirectional glass fiber reinforcements.

A total of 4 bearings were tested; Table 1 gives an overview of the main geometric characteristics of the bearings. In Table 1: $2 b$ is the side of the bearing perpendicular to the holes, $2 a$ is the side parallel to the holes; $A=4 a b$ is the plan area of the bearing; $H$ is its total height; $V=A \cdot H$ is the volume of the bearing; $\varnothing$ is the diameter of the single hole; $V_{\text {holes }}$ is the total volume of the holes.

Figure 1 is a schematic of the tested samples, with dimensions. The four samples have the same geometry (130(2a)x60(2b)x52(H) mm) and an increasing number of holes $(0,4,12,20)$.

Table 1: Description of the tested bearings.

\begin{tabular}{|c|c|c|c|c|c|c|c|c|c|c|c|c|c|}
\hline $\begin{array}{c}\text { N. } \\
\text { test } \\
{[-]} \\
\end{array}$ & $\begin{array}{c}\text { Elastome } \\
r \\
\\
{[-]}\end{array}$ & $\begin{array}{c}\text { Fabri } \\
\text { c } \\
{[-]}\end{array}$ & $\begin{array}{c}\text { Modifies } \\
\text { [-] }\end{array}$ & $\begin{array}{c}2 \mathrm{a} \\
{[\mathrm{mm}} \\
]\end{array}$ & $\begin{array}{c}2 \mathrm{~b} \\
{[\mathrm{~mm}} \\
]\end{array}$ & $\begin{array}{c}\mathrm{A} \\
{\left[\mathrm{mm}^{2}\right.} \\
]\end{array}$ & $\begin{array}{c}\mathrm{H} \\
{[\mathrm{mm}} \\
]\end{array}$ & $\begin{array}{c}\mathrm{V} \\
{\left[\mathrm{mm}^{3}\right]}\end{array}$ & $\begin{array}{c}\mathrm{n}^{\circ} \\
\text { holes } \\
{[-]}\end{array}$ & $\begin{array}{c}\begin{array}{c}\varnothing \\
\text { holes }\end{array} \\
{[\mathrm{mm}]}\end{array}$ & $\begin{array}{c}\text { Vholes } \\
{\left[\mathrm{mm}^{3}\right.} \\
]\end{array}$ & $\begin{array}{c}\begin{array}{c}\text { Vholes } / \\
\mathrm{V} \\
{\left[\mathrm{mm}^{3}\right]}\end{array} \\
\end{array}$ & $\begin{array}{c}\text { Name } \\
{[-]}\end{array}$ \\
\hline 1 & Neoprene & Glass & $\begin{array}{c}\text { Unmodifie } \\
\mathrm{d}\end{array}$ & 130 & 60 & 7800 & 52 & $\begin{array}{c}40560 \\
0 \\
40560\end{array}$ & 0 & 6 & 0.0 & $0.00 \%$ & 130x60 U \\
\hline 2 & Neoprene & Glass & $\begin{array}{c}4 \text { holes } \varnothing 6 \\
12 \text { holes }\end{array}$ & 130 & 60 & 7800 & 52 & $\begin{array}{c}0 \\
40560\end{array}$ & 4 & 6 & 67856 & $1.67 \%$ & $\begin{array}{c}130 \times 604 \mathrm{H} \\
130 \times 60\end{array}$ \\
\hline 3 & Neoprene & Glass & $\begin{array}{c}\varnothing 6 \\
20 \text { holes }\end{array}$ & 130 & 60 & 7800 & 52 & $\begin{array}{c}0 \\
40560\end{array}$ & 12 & 6 & 20357 & $5.02 \%$ & $\begin{array}{c}12 \mathrm{H} \\
130 \times 60\end{array}$ \\
\hline 4 & Neoprene & Glass & $\varnothing 6$ & 130 & 60 & 7800 & 52 & 0 & 20 & 6 & 33929 & $8.37 \%$ & $20 \mathrm{H}$ \\
\hline & & $130 \times 50$ & & & of & & $\Rightarrow$ & $\begin{array}{r}130 \times 6012 \\
\frac{009}{000} \\
\frac{000}{000}\end{array}$ & 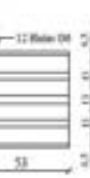 & $=$ & $\begin{array}{l}\frac{130 \times 6020 \mathrm{H}}{0000 \mathrm{C}} \\
\frac{00000}{00000} \\
\frac{00000}{0.0000}\end{array}$ & ב" & \\
\hline
\end{tabular}


Figure 1: Bearing: a) 130x60 U, b) 130x60 4H, c) 130x60 12H, d) 130x60 20H. All the bearings have $52 \mathrm{~mm}$ height.

The holes are made using a drill press (Figure 2), while clamping the sample between two steel plates for alignment. As clear from Table 1, the percentage of removed volume is rather low, being always less than $10 \%$ of the total volume of the bearing.

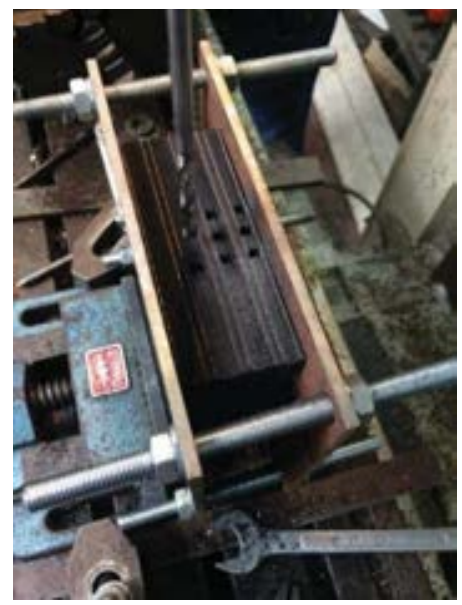

Figure 2: Creation of the pattern of holes in a FREI.

\subsection{Description of the tests}

The shear tests were performed using the test frame shown in Figure 3a. and applying the quasi-static lateral displacement of Figure $3 \mathrm{~b}$ (strain rate of $1 \% / \mathrm{s}$ ). During testing, a vertical load of $18.8 \mathrm{kN}$ was imposed on the bearings. Additional information on the testing apparatus are available in literature [31].

a)

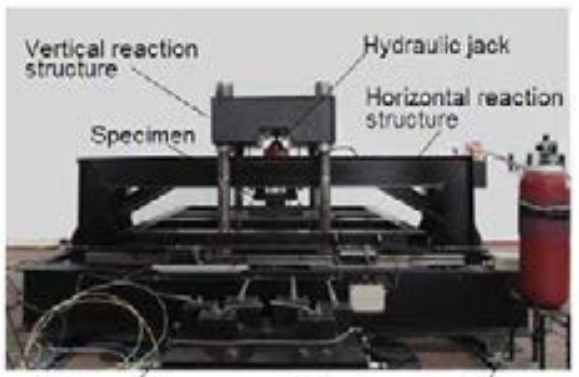

Sliding Table

Hydraulio accumulátor b)

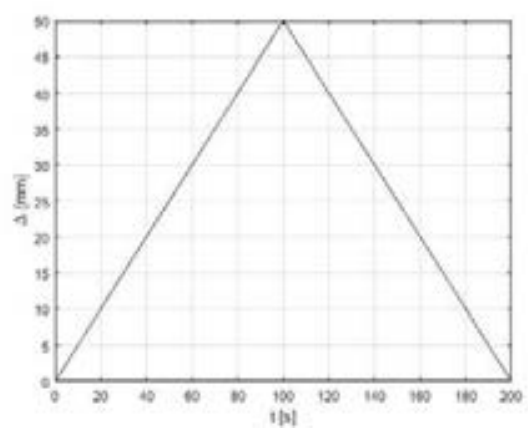

Figure 3: a) Testing frame, b) Time-history of the imposed lateral displacement.

\subsection{Experimental test results}

Figure 4 shows the deformed shape of the bearing during testing. Each column shows three different steps:

- Column 1 - full vertical load and zero lateral displacement.

- Column 2 - full vertical load at a shear deformation of $50 \%$.

- Column 3 - full vertical load at a shear deformation of $100 \%$.

The four rows of the Figure show the four test pieces described in Table 1: Description of the tested bearings. Table 1 (first row: no modification; last row: 20 holes). As intuition suggests, a greater vertical 
deformation corresponds to a larger number of holes. Nevertheless, this variation is minor because of the very low volume of the rubber removed during drilling. All the samples show the onset of a stable roll-over deformation well before $\gamma_{H}=50 \%$.

a)
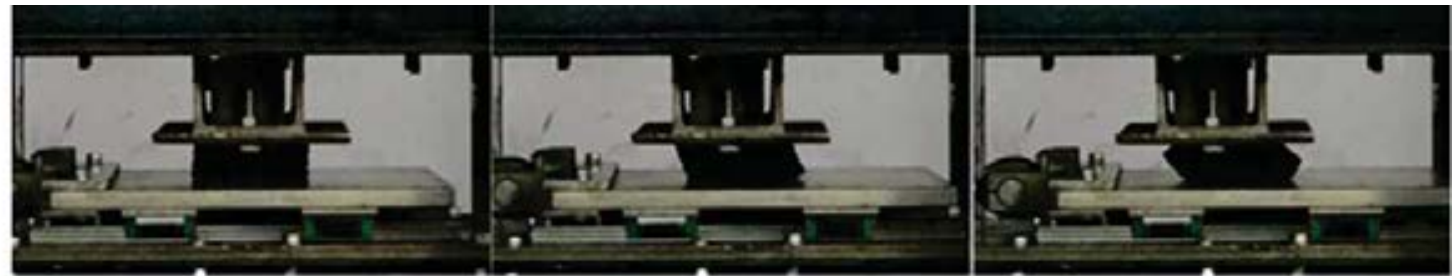

b)
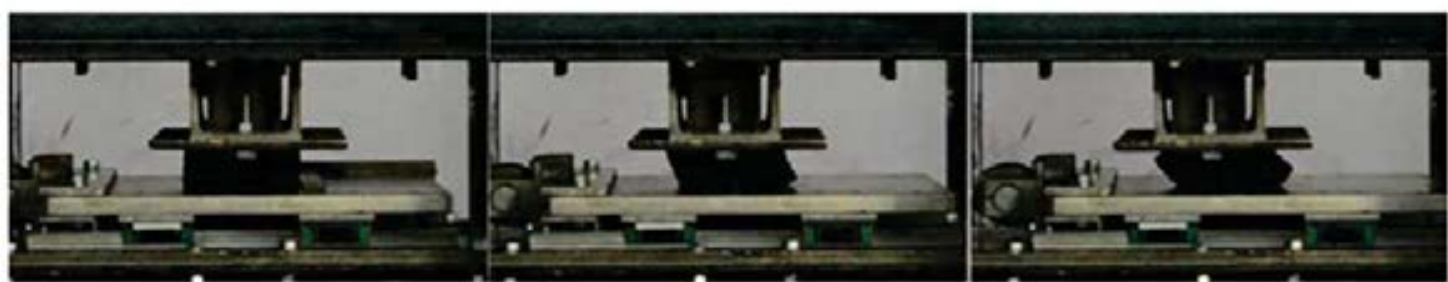

c)
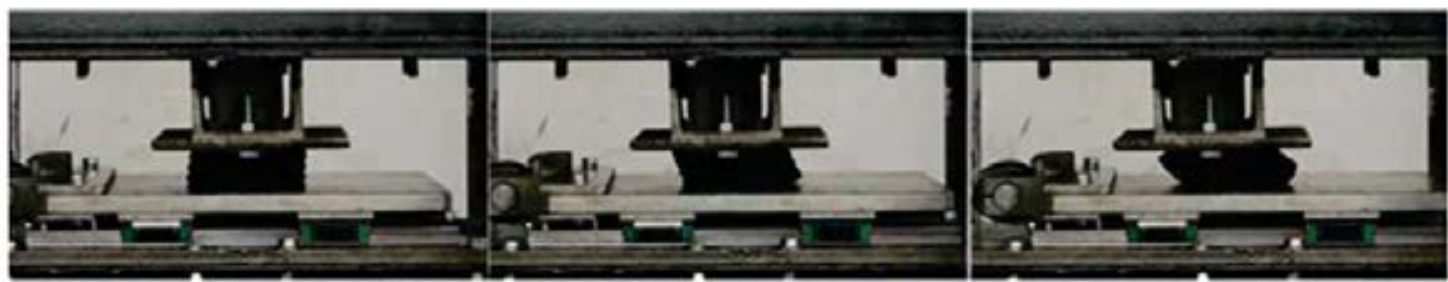

\section{d)}
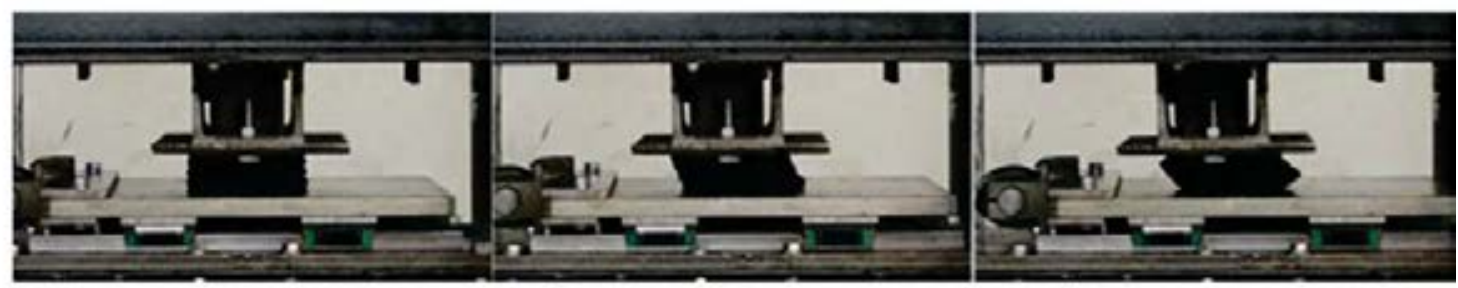

Figure 4: Tested samples at $\gamma_{H}=0 \%$ with full compression, $\gamma_{H}=50 \%$ and $\gamma_{H}=100 \%:$ a) $130 \times 60$ U, b) $130 x 60$ $4 \mathrm{H}$, c) $130 \times 6012 \mathrm{H}$, d) $130 \times 6020 \mathrm{H}$

Figure 5 shows the horizontal force-displacement curves obtained from the experimental tests and the comparison between specimens with the same geometry (130x60x52 mm) and variable number of holes. As clear from this plot, while the peak horizontal load is substantially reduced by the holes, the curve of the bearing with 20 holes shows a positive tangent stiffness, with no instability of the rubber device. Table 2 reports the numerical value of the secant stiffness for each of the samples. 


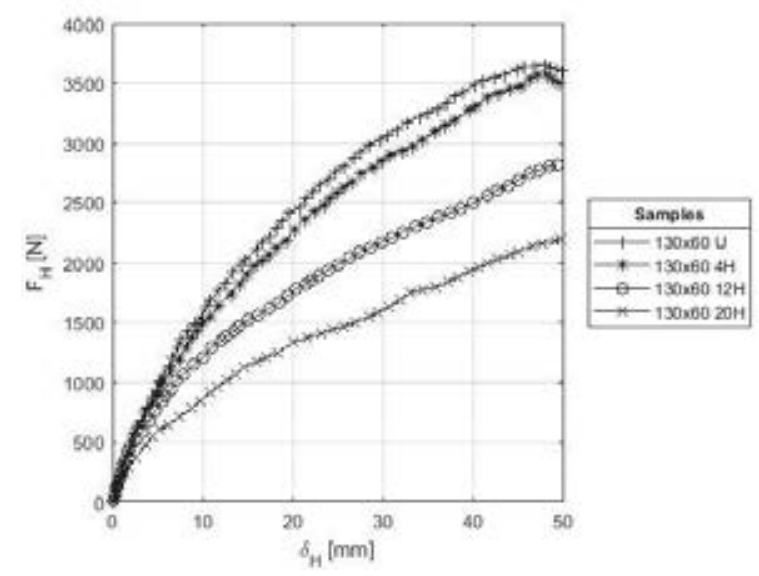

Figure 5: Lateral force displacement response of the tested bearings.

As clear from Figure 5, the sample 130x60 U (top line with + markers) shows a large initial stiffness, with an initial linear response. As the displacement increases past the initial deformation, the bearing shows softening and a peak of the response for a lateral deformation of $45 \mathrm{~mm}\left(\gamma_{H}=86 \%\right)$. A similar result is obtained for the sample with one column of holes (130x60 4H, second curve from the top). The curve differs very little from the one of the unmodified 130x60 U, which is not surprising considering the low percentage of removed volume (1.67\%, see Table 1$)$. The lateral secant stiffness differs no more than $7 \%$ from that of the unmodified sample (Table 2). Again, the response shows negative horizontal stiffness starting from a lateral displacement value of $48 \mathrm{~mm}\left(\gamma_{H}=96 \%\right)$ that is the peak of the lateral force. Compared to the bearing with no holes, an improvement in the lateral response of the sample win 4 holes is evident, as this device has a large range of stable deformations. Because the peak of the response was reached during testing, by increasing the lateral displacement, the bearing $130 \times 604 \mathrm{H}$ would show instability. By increasing the number of holes, the lateral response of the sample changes significantly. For the bearing with 20 holes, the lateral stiffness is largely reduced. In general, the reduction of stiffness is proportional to the percentage of volume removed from the sample (Table 2).

Table 2: Lateral secant stiffness at different imposed deformations, for the tested bearings.

\begin{tabular}{|c|c|c|c|c|c|c|c|}
\hline \multirow{3}{*}{$\begin{array}{c}\Delta \\
{[\mathrm{mm}]}\end{array}$} & \multirow{3}{*}{$\begin{array}{c}130 \mathrm{x} 60 \\
\mathrm{U} \\
K_{H} \\
{[\mathrm{~N} / \mathrm{mm}]}\end{array}$} & \multicolumn{2}{|c|}{$130 \times 604 \mathrm{H}$} & \multicolumn{2}{|c|}{$130 \times 6012 \mathrm{H}$} & \multicolumn{2}{|c|}{$130 \times 6020 \mathrm{H}$} \\
\hline & & $K_{H}$ & $1-\% K_{H}^{U}$ & $K_{H}$ & $1-\% K_{H}^{U}$ & $K_{H}$ & $1-\% K_{H}^{U}$ \\
\hline & & {$[\mathrm{N} / \mathrm{mm}]$} & {$[\mathrm{N} / \mathrm{mm}]$} & {$[\mathrm{N} / \mathrm{mm}]$} & {$[\mathrm{N} / \mathrm{mm}]$} & {$[\mathrm{N} / \mathrm{mm}]$} & {$[\mathrm{N} / \mathrm{mm}]$} \\
\hline 5 & 200 & 188 & $6.20 \%$ & 159 & $20.5 \%$ & 124 & $37.9 \%$ \\
\hline 10 & 156 & 150 & $3.52 \%$ & 118 & $23.9 \%$ & 91 & $41.5 \%$ \\
\hline 15 & 136 & 128 & $5.44 \%$ & 104 & $23.6 \%$ & 77 & $43.0 \%$ \\
\hline 20 & 122 & 114 & $6.51 \%$ & 87 & $29.0 \%$ & 67 & $45.1 \%$ \\
\hline 25 & 111 & 103 & $7.30 \%$ & 79 & $29.1 \%$ & 58 & $47.9 \%$ \\
\hline 30 & 102 & 97 & $5.03 \%$ & 73 & $27.8 \%$ & 54 & $46.9 \%$ \\
\hline 35 & 93 & 87 & $6.50 \%$ & 66 & $29.7 \%$ & 51 & $45.3 \%$ \\
\hline 40 & 87 & 83 & $4.22 \%$ & 63 & $27.7 \%$ & 48 & $44.5 \%$ \\
\hline 45 & 81 & 77 & $4.27 \%$ & 60 & $25.8 \%$ & 47 & $41.7 \%$ \\
\hline 50 & 72 & 71 & $1.37 \%$ & 55 & $23.2 \%$ & 43 & $40.1 \%$ \\
\hline
\end{tabular}


For the bearing with 20 holes, the most significant improvement concerns the overall response of the sample: as can be seen in Figure 5, when the lateral displacement increases, the response remains stable. The bearing shows no softening and the lateral stiffness is always positive: by creating holes in a bearing, it is possible to modify an unstable device to obtain a stable response. This modification of the response is only possible when a larger volume of rubber is remover. If the volume of removed rubber is less than 5\%, the modification of the response is not appreciable. Figure 6 is a plot of the tangent stiffness of each bearing as function of the imposed deformation. As clear from the figure, the first two samples show a softening response with a stable peak around $25 \mathrm{~mm}$ of lateral displacement $\left(\gamma_{H}=50 \%\right.$ ); for the unmodified sample, the tangent stiffness then becomes negative around $45 \mathrm{~mm}$ as mentioned above, while the sample with 4 holes shows a negative tangent stiffness for large deformation. The samples with 12 and 20 holes, show a decreasing stiffness up to $\gamma_{H} \approx 65 \%$, with hardening past this level of deformation.

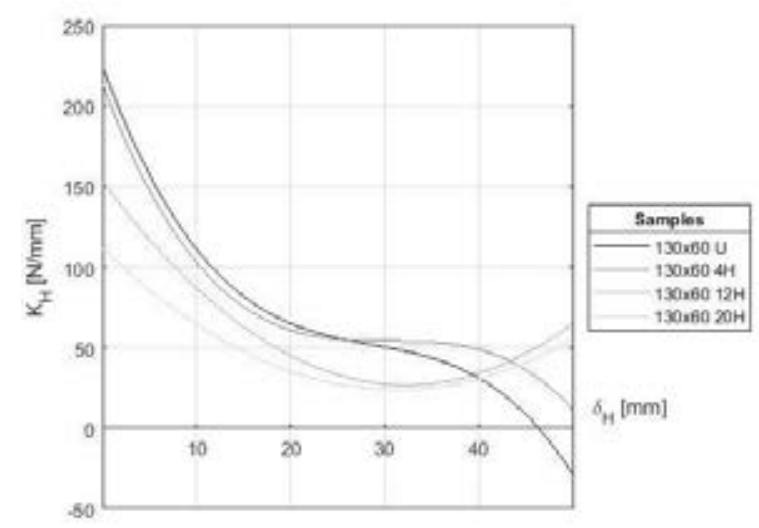

Figure 6: Tangent stiffness vs imposed displacement for the tested devices.

\section{FINITE ELEMENT ANALYSIS}

\subsection{Analysis setting}

The numerical analysis were performed using MSC Marc [32], a general-purpose finite element analysis software. Marc is designed to perform complex non-linear analyses in one, two or three dimensions. This characteristic, combined with the ability to perform complex contact analyses at large strains and the wide choice of hyperelastic material models suitable for elastomers, makes MARC a good choice for numerical analysis of rubber-based devices such as FREIs. Twodimensional plain strain analyses were used for this study. In all the FEAs, the elastomer was modeled using a Neo-Hookean hyperelastic material fully defined by two constants $C_{1}$ and $C_{2}$, where [33]:

$$
\begin{aligned}
& C_{1}=\frac{G}{2} \\
& C_{2}=\frac{\lambda}{2}=\frac{K}{2}-\frac{G}{3}=\frac{K}{2}-\frac{2 C_{1}}{3}
\end{aligned}
$$

with $\mathrm{K}$ being the bulk modulus of the rubber. The fiber reinforcement layers were modeled using a linear elastic material. The layers are fully defined by three parameters: the elastic modulus $E_{f}$, the Poisson's ratio $v_{f}$ and the equivalent thickness of the fiber layer $t_{f}$. All the parameters used for FEAs are detailed in Table 3. 
Table 3: Parameters of the numerical model defined in MARC.

\begin{tabular}{ccccc}
\hline $\begin{array}{c}C_{1} \\
{[\mathrm{MPa}]}\end{array}$ & $\begin{array}{c}C_{2} \\
{[\mathrm{MPa}]}\end{array}$ & $\begin{array}{c}E_{f} \\
{[\mathrm{MPa}]}\end{array}$ & $\begin{array}{c}v_{f} \\
{[-]}\end{array}$ & $\begin{array}{c}t_{f} \\
{[\mathrm{~mm}]}\end{array}$ \\
\hline 0.55 & 1000 & 70000 & 0.1 & 0.1 \\
\hline
\end{tabular}

The elastomeric layers were modeled using a four-node, isoparametric, quadrilateral element, written for plane strain incompressible applications [34]. The reinforcement layers were modeled using an isoparametric, plane strain, 2-node element [34]. The top and bottom supports were modeled using rigid contact lines. The interface between the bearing and the rigid supports has been set as "contact" in MARC with a friction coefficient of 1 ( [5], [6]).

\subsection{FEA results: lateral load-displacement curves}

Figure 7 a shows the horizontal force-displacement curves obtained from FEAs. As clear from Table 4 , the variations of horizontal stiffness when holes are made in the bearings are the same as those obtained from the experimental tests (see Table 2). The FEAs results are consistent with the experimental findings. Starting from the basic 130x60 geometry, the horizontal stiffness is reduced on by $6 \%, 27 \%$ and $45 \%$, by drilling 4 holes on one column, 12 holes on three columns and 20 holes on 4 columns respectively.
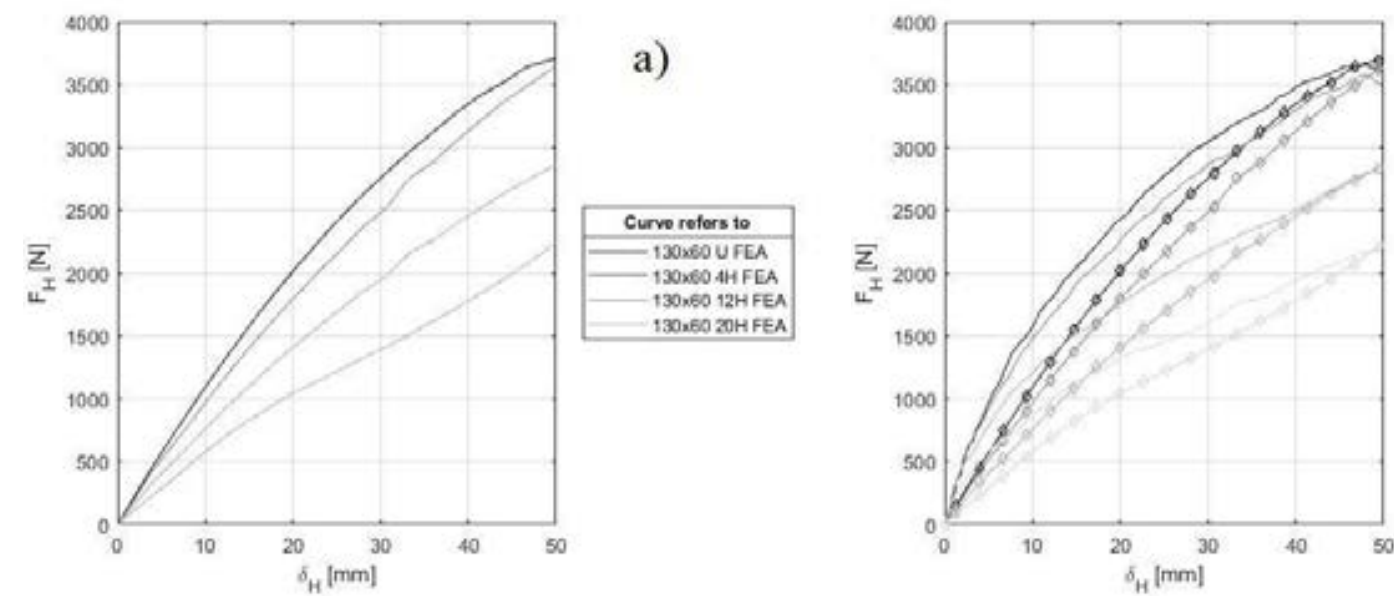

b)

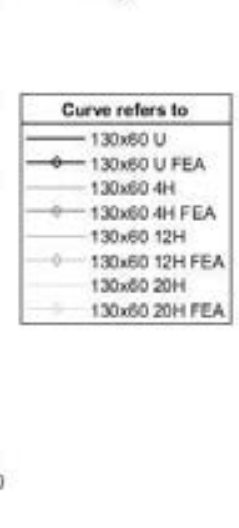

Figure 7: Lateral load-displacement curves: a) 130x60 FEA with variable number of holes, b) comparison of experimental vs FEAs results.

Figure 7a, shows a FEAs response of the bearing similar to that determined with experimental tests.

From the lateral response, it is clear that the stable range for bearing $130 x 6012 \mathrm{H}$ is larger than that of bearing $130 \times 60 \mathrm{U}$, as the latter reaches a peak of the response for a displacement of only $50 \mathrm{~mm}$. Moreover, the bearing with 20 holes shows hardening, with no softening.

Table 4: Lateral secant stiffness at different imposed displacements from FEAs.

\begin{tabular}{|c|c|c|c|c|c|c|c|}
\hline \multirow{4}{*}{$\begin{array}{c}\Delta \\
\Delta \mathrm{mm}]\end{array}$} & \multicolumn{7}{|l|}{$130 \times 60 \mathrm{U}$} \\
\hline & \multirow{3}{*}{$\begin{array}{c}\text { FEA } \\
K_{H} \\
{[\mathrm{~N} / \mathrm{mm}]}\end{array}$} & \multicolumn{2}{|c|}{ 130x60 4H FEA } & \multicolumn{2}{|c|}{ 130x60 12H FEA } & \multicolumn{2}{|c|}{ 130x60 20H FEA } \\
\hline & & $K_{H}$ & $1-\% K_{H}^{U}$ & $K_{H}$ & $1-\% K_{H}^{U}$ & $K_{H}$ & $1-\% K_{H}^{U}$ \\
\hline & & {$[\mathrm{N} / \mathrm{mm}]$} & {$[\mathrm{N} / \mathrm{mm}]$} & {$[\mathrm{N} / \mathrm{mm}]$} & {$[\mathrm{N} / \mathrm{mm}]$} & {$[\mathrm{N} / \mathrm{mm}]$} & {$[\mathrm{N} / \mathrm{mm}]$} \\
\hline 5 & 92 & 85.23 & $7.0 \%$ & 66.82 & $27.1 \%$ & 46.06 & $49.8 \%$ \\
\hline 10 & 102 & 90.54 & $11.5 \%$ & 70.99 & $30.6 \%$ & 54.09 & $47.1 \%$ \\
\hline
\end{tabular}




\begin{tabular}{lccccccc}
\hline 15 & 103 & 91.57 & $11.1 \%$ & 71.79 & $30.3 \%$ & 54.17 & $47.4 \%$ \\
20 & 101 & 89.71 & $10.9 \%$ & 70.34 & $30.1 \%$ & 52.13 & $48.2 \%$ \\
25 & 89 & 79.59 & $10.7 \%$ & 62.40 & $30.0 \%$ & 45.49 & $49.0 \%$ \\
30 & 87 & 78.80 & $9.9 \%$ & 61.78 & $29.4 \%$ & 44.15 & $49.5 \%$ \\
35 & 85 & 78.81 & $7.0 \%$ & 61.79 & $27.1 \%$ & 43.25 & $49.0 \%$ \\
40 & 82 & 76.35 & $6.8 \%$ & 59.86 & $26.9 \%$ & 42.96 & $47.6 \%$ \\
45 & 78 & 74.60 & $4.6 \%$ & 58.49 & $25.2 \%$ & 43.27 & $44.6 \%$ \\
50 & 74 & 72.31 & $2.1 \%$ & 56.69 & $23.2 \%$ & 44.14 & $40.2 \%$ \\
\hline
\end{tabular}

\subsection{FEA results: stress distribution in the bearings}

Figure 8 shows the Von Mises stress contours at three levels of lateral deformation for each of the tested bearings. From left to right, a snapshot is given for $\gamma_{H}=0, \gamma_{H}=50 \%$ and $\gamma_{H}=100 \%$ under the same axial load of $18 \mathrm{kN}$. As clear from Figure 8, the holes change the stress distribution in the device, with the bearing becoming mostly unloaded in the central area, with a large increase of stress in the confined regions of the elastomer. Compared to the unmodified bearing, under pure compression and zero lateral displacement, there is an increase in peak stress in the bearings with 12 holes and 20 holes. These devices show an increase of stress of $27 \%$ and $42 \%$ respectively.

Under large lateral displacements, as the holes in the bearings tend to collapse under the imposed deformation, a stress redistribution happens. For the bearing with one column of holes, at $\gamma_{H}=100 \%$ , the stress level is very similar to that of the unmodified device (Figure 8c, Figure 8f), with a difference of only $3 \%$. The percentage of removed volume with a single column of holes is too low to induce significant changes in the lateral response of the device. By removing at least $5 \%$ of the initial volume, a controlled reduction of the initial stiffness at low deformations can be obtained. Due to the presence of the holes, a redistribution of the stresses at the edge of the bearing in induced. Under large imposed deformations, the small holes created in the samples collapse on themselves, with the bearing showing hardening. 


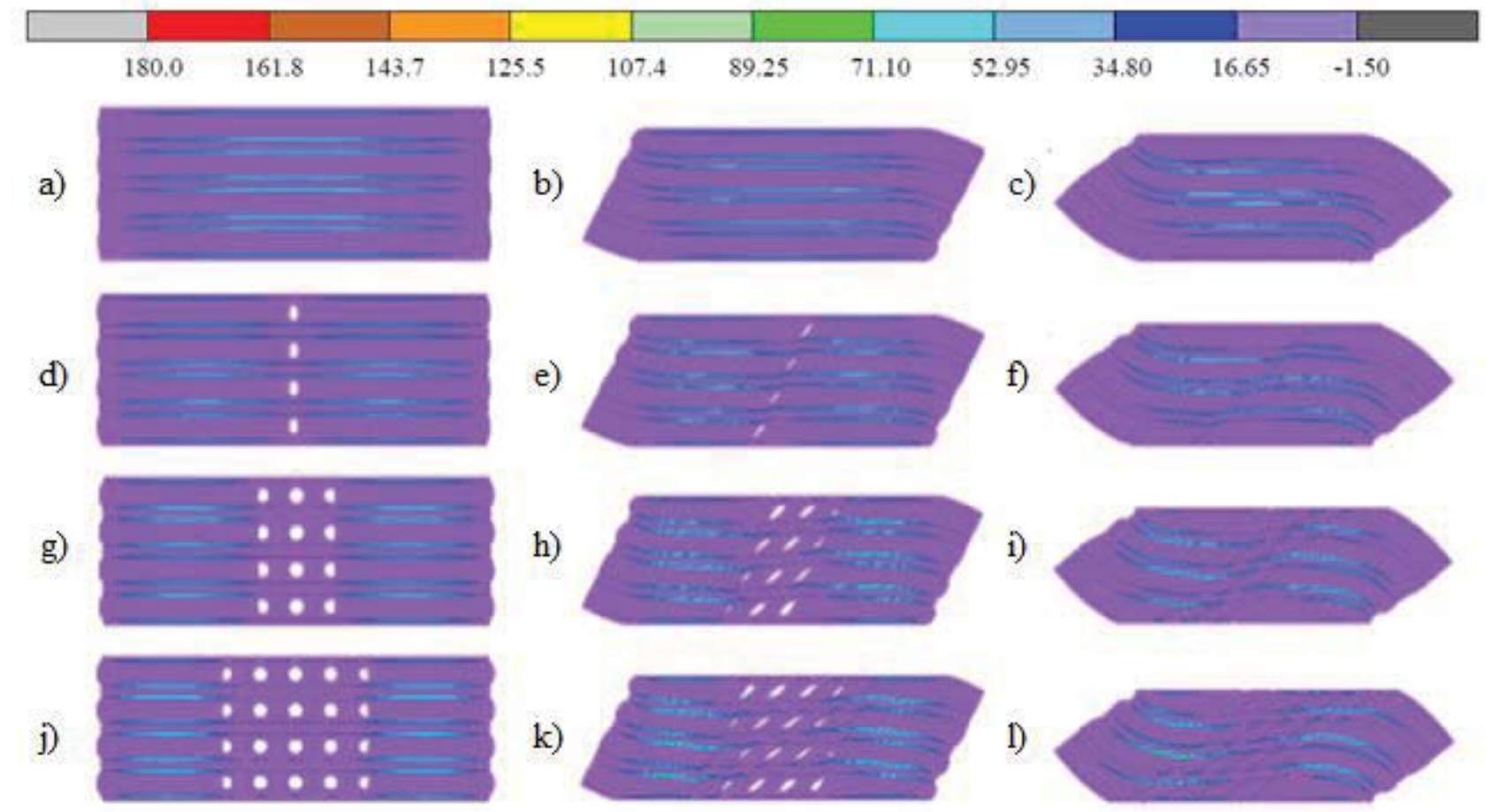

Figure 8: Equivalent Von Mises stresses: a) compression and zero lateral displacement, $130 \times 60 \mathrm{U}$; b) 50\% $\gamma 130 \times 60$

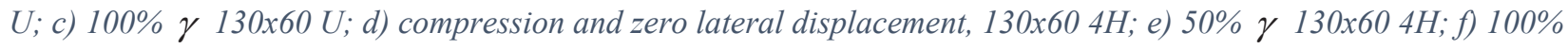

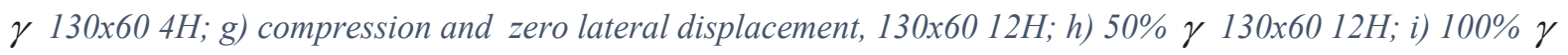

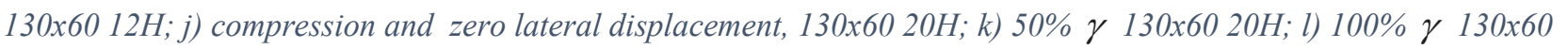
$20 \mathrm{H}$.

\section{CONCLUSIONS}

This study aims to introduce a new rubber-based technology for base isolation of lightweight structures. Experimental and FEAs show that it is possible to obtain an improvement in the response of FREIs by creating simple patterns of holes in the elastomer. It was found that by removing at least $5 \%$ of the initial volume of rubber an improvement in the lateral response of the device can be obtained, to get:

i. a controlled reduction of the horizontal stiffness $(6 \%, 27 \%$ and $45 \%$ reduction with 4,12 and 20 holes respectively),

ii. an extension of the stable range of deformation of the bearing. With imposed deformations up to $\gamma_{H}=100 \%$, the bearing always showed a positive horizontal stiffness. Devices which are unstable beyond a deformation of $\gamma_{H} \approx 90 \%$ show a larger stable range when modified with lateral holes.

FEAs confirmed the experimental results. The stress analysis of the bearing helps understanding the behavior of the modified FREIs under combined axial and shear loads. As the number of holes (columns of holes) increases, the area close to the holes becomes stress free. Under large imposed deformations, the small holes created in the bearing collapse, and a redistribution of stresses occurs in the device. Additional studies are needed to investigate the effect of the aspect ratio of the bearing, of different materials and geometries on the lateral and vertical response of the devices when pattern of holes of different sizes and shapes are created. 


\section{REFERENCES}

[1] J. M. Kelly, "Analysis of Fiber-Reinforced Elastomeric Isolators," Journal of Seismology and Earthquake Engineering, vol. 2, no. 1, 1999.

[2] B. Y. Moon, G. J. Kang, B. S. Kang and J. M. Kelly, "Design and manufacturing of fiber reinforced elastomeric isolator for seismic isolation," Journal of Materials Processing Technology, vol. 130, no. 131, pp. 145-150, 2002.

[3] A. Calabrese, D. Losanno, M. Spizzuoco, S. Strano and M. Terzo, "Recycled Rubber Fiber Reinforced Bearings (RR-FRBs) as base isolators for residential buildings in developing countries: The demonstration building of Pasir Badak, Indonesia," Engineering Structures, no. 192, pp. 126-144, 2019.

[4] D. Losanno, A. Calabrese, I. E. Madera Sierra, M. Spizzuoco, J. Marulanda, P. Thomson and G. Serino, "Recycled Versus Natural-Rubber Fiber-Reinforced Beearings For base Isolation: Review of the Experimental Findings," Journal of Earthquake Engineering, 2020.

[5] J. M. Kelly and D. Konstantinidis, "Effect of Friction on Unbonded Elastomeric Bearings," Journal of Engineering Mechanics, vol. 135, no. 9, pp. 953-960, 2009.

[6] H. Toopchi-Nezhad, M. J. Tait and R. G. Drysdale, "Testing and modeling of square carbon fiberreinforced elastomeric seismic isolators," Structural Control and Health Monitoring, vol. 15, pp. 876900, 2007.

[7] H. Toopchi-Nezhad, M. J. Tait and R. G. Drysdale, "Bonded versus unbonded strip fiber reinforced elastomeric isolators: Finite element analysis," Composite Structures, vol. 93, pp. 850-859, 2011.

[8] J. M. Kelly and A. Calabrese, "Mechanics of fiber reinforced bearings," PEER Report 101, Pacific Earthquake Engineering Research Center, College of Engineering, University of California Berkeley, 2012.

[9] N. C. Van Engelen, M. J. Tait and D. Konstantinidis, "Model of the Shear Behavior of Unbonded Fiber-Reinforced Elastomeric Isolators," Journal of Structural Engineering, vol. 141, no. 7, 2015.

[10] N. Vaiana, R. Capuano, S. Sessa, F. Marmo and L. Rosati, "Nonlinear dynamic analysis of seismically base-isolated structures by a novel OpenSees hysteretic material model," Applied Sciences, vol. 11, no. 3, p. $900,2021$.

[11] N. Vaiana, D. Losanno and N. Ravichandran, "A novel family of multiple springs models suitable for biaxial rate-independent hysteretic behavior," Computers \& Structures, vol. 244, p. 106403, 2021.

[12] N. Vaiana, S. Sessa and L. Rosati, "A generalized class of uniaxial rate-independent models for simulating asymmetric mechanical hysteresis phenomena," Mechanical Systems and Signal Processing, vol. 146, p. 106984, 2021.

[13] N. Vaiana, S. Sessa, M. Paradiso, F. Marmo and L. Rosati, "An efficient computational strategy for nonlinear time histiry analysis of seismically base-isolated structures," in Proceedings of XXIV AIMETA Conference 2019, 2019.

[14] F. Marmo, S. Sessa, N. Vaiana, D. De Gregorio and L. Rosati, "Complete solutions of three dimensional problems in transversely isotropic media," Continuum Mechanics and Thermodynamics, vol. 32, no. 3, pp. 775-802, 2020. 
[15] D. Losanno, I. E. Madera Sierra, M. Spizzuoco, J. Marulanda and P. Thomson, "Experimental performance of unbonded polyester and carbon fiber reinforced elastomeric isolators under bidirectional seismic excitation," Engineering Structures, no. 209, 2020.

[16] D. Losanno, F. Palumbo, A. Calabrese, T. Barrasso and N. Vaiana, "Preliminary investigation of aging effects on Recycled Rubber Fiber Reinforced Bearings (RR-FRBs)," Journal of Earthquake Engineering, 2021.

[17] D. Losanno, I. E. Sierra Madera, M. Spizzuoco, J. Marulanda and P. Thomson, "Experimental assessment and analytical modeling of novel fiber-reinforced isolators in unbounded configuration," Composite Structures, no. 212, pp. 66-82, 2019.

[18] D. Losanno, N. Ravichandran, F. Parisi, A. Calabrese and G. Serino, "Seismic performance of a LowCost base isolation system for unreinforced brick Masonry buildings in developing countries," Soil Dynamics and Earthquake Engineering.

[19] D. Losanno, M. Spizzuoco and A. Calabrese, "Bidirectional shaking-table tests of unbonded recycledrubber fiber-reinforced bearings (RR-FRBs)," Wiley, 2019.

[20] I. E. Madera Sierra, D. Losanno, S. Strano, J. Marulanda and P. Thomson, "Development and experimental behavior of HDR seismic isolators for low-rise residential buildings," Engineering Structures, no. 183, pp. 894-906, 2019.

[21] A. Calabrese, M. Spizzuoco, S. Galano, N. Tran, S. Strano and M. Terzo, "A Parametric Study on the Stability of Fiber Reinforced Rubber Bearings Under Combined Axial and Shear Loads," Engineering Structures, vol. 227, p. 111441, 2020.

[22] S. Galano, D. Losanno and A. Calabrese, Stability Analysis of Unbonded Fiber Reinfoced Isolators of Square Shape, In proceeding, 2020.

[23] F. Naeim and J. M. Kelly, Design of seismic isolated structures, John Wiley \& Sons, Inc., 1999.

[24] J. M. Kelly and D. Konstantinidis, Mechanics of Rubber Bearings for Seismic Isolation and Vibration Isolation, John Wiley and Sons, Ltd, 2011.

[25] N. C. Van Engelen, M. J. Tait and D. Konstantinidis, "Vertical response behaviour of stable unbonded fiber reinforced elastomeric isolators (SU-FREIs) with holes in the loaded surface," in Canadian society for civil engineering annual general conference, Edmonton, Canada, 2012.

[26] N. C. Van Engelen, M. J. Tait and D. Konstantinidis, "Horizontal Behaviour of Stable Unbonded Fiber Reinforced Elastomeric Isolators (SU-FREIs) with Holes," in World Conference on Earthquake Engineering, Lisboa, 2012.

[27] N. C. Van Engelen, P. M. Osgooei, M. J. Tait and D. Konstantinidis, "Experimental and finite element study on the compression properties of Modified Rectangular Fiber-Reinforced Elastomeric Isolators (MR-FREIs)," Engineering Structures, no. 74, pp. 52-64, 2014.

[28] P. M. Osgooei, N. C. Van Engelen, D. Konstantinidis and M. J. Tait, "Experimental and finite element study on the lateral response of modified rectangular fiber-reinforced elastomeric isolators (MRFREIs)," Engineering Structures, no. 85, pp. 293-303, 2015. 
[29] C. Tran, A. Calabrese, M. F. Vassiliou and S. Galano, "A simple strategy to tune the lateral response of unbonded Fiber Reinforced Elastomeric Isolators (FREIs)," Engineering Structures, no. 222, pp. 111$129,2020$.

[30] Caltrans, Caltrans Standard Plans, State of Californnia: California Department of Transportation, 2018.

[31] G. Palli, S. Strano and M. Terzo, "A novel adaptive-gain technique for high-order sliding-mode observers with application to electro-hydraulic systems," Mechanical Systems and Signal Processing, no. $106875,2020$.

[32] MSC.Software Corporation, Volume A: Theory and User Information, Santa Ana, CA, USA, 2017.

[33] MSC.Software Corporation, MAR103 Experimental Elastomer Analysis, Santa Ana, CA, USA, 2017.

[34] MSC.Software Corporation, Volume B: Element Library, Santa Ana, CA, USA, 2017. 